\title{
Analysis of the most commonly used platforms for the management of construction projects in Spain
}

\author{
Nuria Forcada, Miquel Casals, Xavier Roca \\ Polytechnic University of Catalonia, Department of Construction Engineering \\ C/Colom 11, Edifici TR-5, 08221 Terrassa, Barcelona, Spain \\ nuria.forcada@upc.es
}

\begin{abstract}
The 1990s have seen a technological shift in the construction sector from IT driven solutions to IT enabling ones.

Not only IT companies but also construction companies are continually investing, evaluating and focusing on new technologies to create collaborative spaces among different participants geographically dispersed and to share information among partners in the design phase, in the supply chain, in the construction process, etc.

Many different services are there in Internet for the construction sector that fall into four categories:

One of the services are electronic brochures that are portals based around manufactured product and tend to duplicate paper-based catalogues.

There are also on-line portals, which enable e-commerce and have links to Standards, industry news, databases of selected professionals in the industry, etc.

For the management of construction projects we can find project collaboration services or extranets that are focused on tools and services that make it easier to manage the AEC projects. Common services include backing up files, keeping a document revision history, tracking who accesses what files.

Finally, there are full service portals. In addition to project management tools, full-service portals provide services such as community forums where you can chat with other project managers and share knowledge resources. Other services may include online catalogs for finding materials and subcontractors.

In this Paper we will expose the different kind of IT services that are available for the construction sector in Spain and some examples of how various companies have taken advantage of this new methodologies
\end{abstract}

KEYWORDS: Construction Project Management, Platforms, Web services.

\section{INTRODUCCIÓN}

Project management and projects are not new concepts but projects today are far more complicated than ever before. They involve larger capital investments, embraces several disciplines, widely dispersed project participants, tighter schedules, stringent quality standards, etc. These factors coupled with high-speed developments in Information and Communication Technology (ICT) have influenced project management practices to take a new turn taking advantage of newly developed management tools and the latest technology (Alshawi, 2001).

Nowadays, the handling of information and its access has been converted into essential factors for the economical development and business success. In the last years, Information Society and basically Internet, has become the main information transmission and communication media among companies.
In Spain, the construction sector holds more than the 7\% of the GNP (Gross National Product) and more than 270.000 business. Moreover, the giants of the sector (less than about ten companies) share out around the $10 \%$ of the invoicing while the $90 \%$ are hold by an enormous quantity of SMES (Small and Medium Enterprises) and autonomous. Probably, the construction industry is the geographically most dispersed and involves a big quantity of small and medium enterprises. The variety of professionals in a project can easily cover dozens of disciplines from architecture, engineering to installations and demolition, all with very different information requisites.

Both, the improvement of IT and the characteristics of the construction sector have lead to the creation of many different web services focused on the construction sector. 


\section{BACKGROUND}

As there are many services offered not only for the management of construction projects but also for information, marketing, ordering, etc. We will start defining some terms so as to clarify the following information.

\section{Electronic business}

Includes

- electronic trading of physical goods and intangibles such as information,

- all trading steps such as online marketing, ordering, payment, and support for delivery

- electronic provision of services, such as aftersales support or online legal advice

- electronic support for collaboration between companies, such as collaborative design

\section{Electronic commerce}

Is considered as the subpart of e-business that is focused on e-procurement, e-buying, e-payment, etc, representing 'punctual' operations of short duration.

\section{Portal}

Web sites targeted at specific audiences and communities, providing content aggregation, relevant information, collaboration services and application access. A portal should provide:

- Connection to the resources of the Internet through search engines, shopping engines and other utilities

- Content like appropriate news, legislation, etc.

- Commerce involving access to electronic shopping and other commercial activities

- Community of interests that are basically tools to enable participants to interact.

\section{Electronic marketplaces}

A web site that offers transaction functionality between two or more companies. Usually, it offers additional functionalities like product catalogue management, biddings, etc.

Electronic marketplaces are one of the most significant developments of the Internet age to date.

\section{Application Services Providers (ASP)}

These services are third-party entities that manage and distribute software-based services and solutions to customers across a wide area network from a central data center. In essence, ASPs are a way for companies to outsource some or almost all aspects of their information technology (Martinez, 2002).

\section{THE BEGGINING OF INTERNET IN CONSTRUCTION}

The main reason why the construction sector has entered in Internet is the own potential of this market. In fact, the proportion of GNP the Spanish construction market is one of the biggest. Moreover, the fragmentation of this sector let everybody imagine an Internet portal capable of grouping together all SMEs (Salvatierra, B, 2002). In Europe, the construction sector presents a great fragmentation due to, partially, the absence of normalization. Internet is a global environment and requires a unified working process.

In Spain the creation of specialized portals in the construction sector has a considerable delay in relation to other countries.

Recently, the development of portals for AEC and the infrastructure to support them has increased a lot both at commercial and research level.

Many construction portals have been launched in Spain over the last two years, in line with similar trends across all industries. Several of these portals failed within a short period of time indicating the tight marketplace within which they are competing, and the lack of known business models for successful systems.

\section{INTERNET AND PROJECT MANAGEMENT}

The advent of various new technologies, with the potential to address some of the limitations facing current project management practices has created a major impact on many organizations. Foremost of the new technologies is the Internet, which offers the platform for more effective communication. Many businesses throughout the world use this technology as a channel to communicate or to exchange information. The Internet has also embraced the construction industry, that it could be used as an efficient tool for communication to bring together the widely dispersed project participants and multinational project teams. On the other hand, a few are under the impression that the Internet provides an automatic solution to the fractured communication system in construction. 


\section{INTERNET AND COMUNICATION}

Communication is a broad term. We can distinguish between: information access and interactive communication.

Some of the internet services for the construction sector are based on 'Information Access', there are portals where groups of interested people can visualize information of an specific topic like legislation, databases, advertising, events, etc.

Information Portals are those portals for more general use, offering information as main resource, with classified links to other sites, without transaction functionality among companies.

Other Internet services are based on interactive communication and basically on data management so as to carry out the management of the constructive project. Enterprise Portals are those portals centered on the operations of an enterprise offering information and transaction functionality for stakeholders of a since company. Project management features can be also available. This kind of site can be based on Internet, Intranet or Extranet or in a combination of these ones.

Data exchange can be generically defined as the process of transferring relevant information between different construction parties with the aim of minimizing data re-entry and duplication. Data exchange can take place across several organizations, construction applications, professionals, etc. Such an exchange involves different types and amounts of information depending on the nature of the organization, experience, project, etc.

\section{THE EVOLUTION}

It's nearly 10 years from the beginning of the mass commercialization of Internet, the media that has progressed in an exponential way.

Firstly, in its origins, the use of Internet was basically to show information, a place where users and companies could place their personal web pages free. The main objective was to disseminate the image and characteristics of their company.

The evolution tended to join communities of users, professionals, etc. in different spaces, which was called Virtual Communities and Portals. A portal is 'The web page where to aggregate contents and functionalities, organized in a way that facilitates the navigation and gives the users an entrance to the Net with a huge range of options'. Therefore, users have the services and products of an area of knowledge that might need all together.

Later, companies felt the necessity to offer services (included sells trough Internet, called ecommerce) and improve their contents. Now, the strategy of Internet is not only to 'be' there but also to 'do'.

Not only after some years of the beginning of the first portals, the construction sector entered in Internet. At the beginning of the year 2000 the first specialized portals in the area of construction in Spain shown up. When the first five or six construction portals $\mathrm{b} 2 \mathrm{~b}$ began to run, the big Spanish construction companies created their portals b2b. Their objective was to create platforms for the electronic commerce centered basically in construction materials.

In 2001 a dozen of portals appeared in the construction sector, like Uralita, E-difica, Build2Build, BuildCom, Urbaniza or Bricsnet.

The question is 'Is there enough market for too many specialized portals?' If the users have too many similar webs with the same services and very little difference between them, it generates confusion and dispersion. Due to, in less than a year, a great quantity has disappeared and the others have fused.

For Vicente Martinez, general director of Germinus, the success of the specialized portals depends on the inverted money, as well as high level of professional contents of information. Portals must have a potent technologic partner in Internet, a consultant that knows the net and business models in Internet and on top of all; it must count with the support of a sectorial leader (Gilarranz L, 2002).

The fact that the market tends to a globalization is that in March 2002 the big portals of the Spanish construction fused in a new company called Obralia. Small and medium enterprises are those who will benefit from those portals to be able to have access to a big market and use the same technology as the big ones. The main objective of this new stage is to offer not only the transactional tool best adapted to a sector in which constructors and suppliers could buy and sell materials through Internet with all its advantages but also web project management services.

What about the future? Is it possible in a near future to make all the professionals involved in all the stages of the construction process walk close to their computer connected to Internet? This is the direction that construction must follow. It should tend to a renovation and a training of all the participants of the construction process. 


\section{DESCRIPTION OF THE MOST COMMONLY USED WEB SERVICES}

Table 5. Summary of the main construction portals and their services

\begin{tabular}{|c|c|c|c|c|c|c|c|c|c|c|c|c|c|}
\hline & 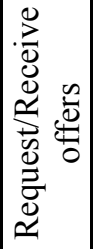 & 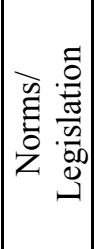 & 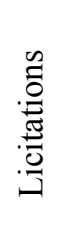 & 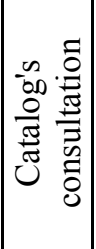 & 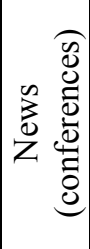 & 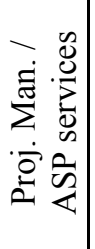 & 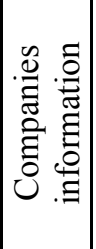 & 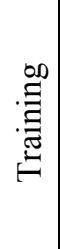 & $\begin{array}{l}\grave{D} \\
\stackrel{0}{0} \\
\stackrel{8}{4}\end{array}$ & 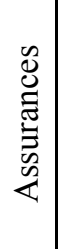 & 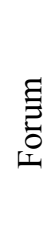 & 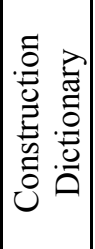 & 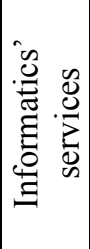 \\
\hline $\begin{array}{l}\text { Aconstruir } \\
\text { http://www.aconstruir.com/ }\end{array}$ & $*$ & $*$ & & & $*$ & & & & & & & & \\
\hline $\begin{array}{l}\text { BravoBuild España } \\
\text { http://www.bravobuild.es/ }\end{array}$ & $*$ & $*$ & $*$ & $*$ & $*$ & & $*$ & & $*$ & & & & $*$ \\
\hline $\begin{array}{l}\text { Bricsnet Ibérica } \\
\text { http://www.bricsnet.es/ }\end{array}$ & & & & & & $*$ & & & & & & & \\
\hline $\begin{array}{l}\text { Buildnet } \\
\text { http://www.buildnet.es/ }\end{array}$ & & $*$ & $*$ & $*$ & $*$ & & $*$ & & & & & & \\
\hline $\begin{array}{l}\text { CartagoExchange } \\
\text { http://www.cartagoexchange.com/ }\end{array}$ & & & & & $*$ & & & & & $*$ & & & \\
\hline $\begin{array}{l}\text { CEW } \\
\text { http://www.civileng.com/ }\end{array}$ & & $*$ & & & $*$ & & & $*$ & & & & & $*$ \\
\hline \multicolumn{14}{|l|}{$\begin{array}{l}\text { Construdata21 } \\
\text { http://www.construdata21.com/ }\end{array}$} \\
\hline $\begin{array}{l}\text { Construfácil } \\
\text { http://www.construfacil.com/ }\end{array}$ & $*$ & $*$ & & $*$ & $*$ & & $*$ & & & & & & \\
\hline $\begin{array}{l}\text { Construnario } \\
\text { http://www.construnario.com/ }\end{array}$ & & $*$ & & & $*$ & & & & & & $*$ & $*$ & \\
\hline $\begin{array}{l}\text { ConstruNet } \\
\text { http://www.construnet.net/ }\end{array}$ & & $*$ & & & $*$ & & & & & & & & $*$ \\
\hline $\begin{array}{l}\text { Construplaza.com } \\
\text { http://www.construplaza.com/ }\end{array}$ & $*$ & $*$ & $*$ & $*$ & $*$ & & & & & & & & \\
\hline $\begin{array}{l}\text { Construred Global } \\
\text { http://www.construred.com/ }\end{array}$ & $*$ & & $*$ & $*$ & & & & & $*$ & $*$ & & & $*$ \\
\hline $\begin{array}{l}\text { LaNaveIndustrial.com } \\
\text { http://www.lanaveindustrial.com/ }\end{array}$ & $*$ & & & & & & & & & & & & \\
\hline $\begin{array}{l}\text { Miliarium Aureum } \\
\text { http://www.miliarium.com/ }\end{array}$ & & $*$ & $*$ & & $*$ & & & & & & & & $*$ \\
\hline $\begin{array}{l}\text { Obracivil.com } \\
\text { http://www.obracivil.com/ }\end{array}$ & & & $*$ & & $*$ & & & & & & & & \\
\hline $\begin{array}{l}\text { Obralia } \\
\text { http://www.obralia.com/ }\end{array}$ & $*$ & $*$ & $*$ & & & $*$ & & $*$ & & $*$ & & & $*$ \\
\hline $\begin{array}{l}\text { Obrasyreformas.com } \\
\text { http://www.obrasyreformas.com/ }\end{array}$ & $*$ & & & & $*$ & & & & & & $*$ & & $*$ \\
\hline $\begin{array}{l}\text { Rentamaquina.com } \\
\text { http://www.rentamaquina.com/ }\end{array}$ & $*$ & & & $*$ & $*$ & & & & & & & & $*$ \\
\hline $\begin{array}{l}\text { Structuralia } \\
\text { http://www.structuralia.com// }\end{array}$ & & $*$ & & & $*$ & $*$ & & $*$ & & & & & \\
\hline $\begin{array}{l}\text { Todo Construcción } \\
\text { http://www.todoconstruccion.com/ }\end{array}$ & & & & $*$ & $*$ & & & & & & $*$ & & \\
\hline
\end{tabular}

In this table the main construction portals and their services are summarised.

Construplaza provides general information about the sector, events, and legislation. As emarketplace, the site offers services of e- catalogues and b2b transactions. Obralia offers ASP services to sell and buy products, management of offers and demands and ecataloguing system. Construnario is an Internet portal with a construction-oriented dictionary and 
searcher; Structuralia is also an Internet portal with general information (events, publications, software, job opportunities, etc). The site offers ework services to support outsourcing and workflow as well as e-learning services.

Afterwards, we classify these services into different categories.

\section{CATEGORIES AND CHARACTERISTICS OF THE CURRENT AVAILABLE WEB SERVICES FOR CONSTRUCTION}

The portals that have been launched in the construction sector in Spain, generally fall into four categories

- electronic brochures

- e-commerce portals

- project collaboration services, and

- full service portals

\subsection{Portals based on electronic brochures}

Portals based around manufactured products form the majority of existing portals. In general they tend to duplicate paper-based catalogues, in several cases to the extent that they scan paperbased catalogues to provide their service. The benefit of this approach is fairly low; the only added benefit over a paper system (assuming that speed of access to information is fairly comparable) is that updates are immediately visible to all users. The presence in Internet is reduced precisely to this; only bring together corporative information of the services that they offer offline.

Table 1. Examples of portals based on electronic brochures

\begin{tabular}{|l|}
\hline \multicolumn{1}{|c|}{ Electronic brochures } \\
\hline CartagoExchage \\
\hline Construdata21 \\
\hline Construnet \\
\hline Obracivil \\
\hline Todo Construccion \\
\hline Construplaza \\
\hline La Nave Industrial \\
\hline Obrasyrformas \\
\hline
\end{tabular}

\subsection{E-commerce portals}

Some portals are enabling e-commerce for purchase of selected products, and a very small number are providing for selection of products based on their performance attributes. To augment these services the portals often tie in a selected set of related information services, for example, links to Standards, industry news, databases of selected professionals in the industry, etc. A major criticism of these sites is that they lack comprehensiveness. This is often true even for their major information content (i.e. manufactured products), but more especially true for their associated services, which tend to have a minute portion of the information available to the industry.

Table 2. Examples of on-line

\begin{tabular}{|l|}
\hline \multicolumn{1}{|c|}{ E-commerce portals } \\
\hline A construir \\
\hline BravoBuild España \\
\hline Construplaza \\
\hline CEW \\
\hline Construfacil \\
\hline Obralia \\
\hline
\end{tabular}

\subsection{Project collaboration services}

Project collaboration services focus on tools and services that make it easier to manage the AEC design projects. Common services include backing up files, keeping a document revision history and tracking who accesses what files. Such sites also offer online document viewing, online markup, and plotting.

All existing web-based project management software are based on exchanging and sharing documents. Information can be stored in a single database where users can view, track and manipulate as and when required.

Currently, there are many commercially available software to cater for different types of documentbased data exchange. They all come under the umbrella of web-based project management. These software cater for the application needs of the different stages of the project life cycle: i.e. the tender stage (when tender documents are exchanged between clients, contractors, subcontractors, etc.) and the design and construction stages, (where drawings and other documents are exchanges between project partners), and the construction stage (when buying and selling of building materials take place over internet).

Different collaboration services are being used over Europe: ProjectNet (Bidcom), ProjectCenter (Bricsnet), ProjectsOnline (BuildOnline), ProjectPoint (Buzzsaw), etc. 
Some of these services run in Spain but they don't have national suport like ProjectsOnline, ProjectNet., etc.

There are other project collaboration services that run in Spain and have also national support like Bricsnet and Structuralia.

Many big companies in Spain, like Fomento de Construcciones y Constratas, IDOM, Bobis, etc. have created their own Intranet for the management of their projects.

Table 3. Examples of portals based on project collaboration services

\begin{tabular}{|l|}
\hline \multicolumn{1}{|c|}{$\begin{array}{c}\text { Project collaboration } \\
\text { services }\end{array}$} \\
\hline ProjectNet \\
\hline Bricsnet \\
\hline Structuralia \\
\hline BuildOnline \\
\hline
\end{tabular}

\subsection{Full service portals}

In addition to project management tools, fullservice portals provide services such as community forums where you can chat with other project managers and share knowledge resources. Other services may include online catalogs for finding materials and subcontractors. This portals based around project information management provide a service to industry by enabling virtual teams to be formed from all participants in a project where project documents are shared between participants in a very immediate fashion. These portals also tend to offer associated services along the same lines as the manufactured product portals and with the same deficiencies.

In the next table, there is a list of portals based on the management of construction projects that area available in Spain at the present.

\section{THE FUTURE}

The online service industry will continue to solidify, and as time goes by the two main hosting service types - project collaboration services and full-service portals- will likely blend into one.

Managing AEC projects online is growing in popularity. As these services mature, the tools and features offered are refined to meet the most common needs.

\section{CONCLUSIONS}

The construction sector in Spain has a very suitable characteristics to get profit from the possibilities that Internet offers for the management and basically for SMEs, whom the electronic commerce can help them to increase their competitiveness in the market and reduce costs.

There are more than 270.000 construction companies in Spain and $80 \%$ are SMEs with less than 6 employees.

Nevertheless, this possible market is not only to offer tools and platforms for electronic commerce but also to help the management of the whole construction process trying to integrate all the stages and all the participants.

Internet can reduce distances, facilitate communication and collaboration, etc but all this benefits are conditioned by the other implicated parts that that must be prepared to redesign their business.

\section{REFERENCES}

Alsawi, M. \& Ingiride, B., 2001. Web-Enabled Project Management. University of Salford.

Gilarranz, L. 2002. La construcción entra en Internet. Expansión directo

Lopez-Bassos V, 2001, The truth behind the web, oecd Observer.

Martinez, M. 2002. D.5.1. Electronic Business in the AEC sector. ProdAEC, European Network for IT in Architecture, Engineering and Construction IST-2001-32035

Salvatierra, B, 2002, El B2B llega a la construcción. Internet \& Negocios. Pp 70, 73

SEDISI, 2001, Study of the level of IT 